Original article

\title{
Detection of Toxoplasma gondii infection among diabetic patients in Turkey
}

\author{
Semra Ozcelik ${ }^{\mathrm{a}}$, Mehtap Alim ${ }^{\mathrm{b}}$, Necati Ozpinar, ${ }^{\mathrm{c}, *}$ \\ ${ }^{a}$ Bezmialem Vakif University, Health Sciences Institute, Istanbul, Turkey \\ ${ }^{\mathrm{b}}$ Cumhuriyet University, Faculty of Medicine, Department of Parasitology, Sivas, Turkey \\ ${ }^{\mathrm{c}}$ Hatay Mustafa Kemal University, Faculty of Health Sciences, Hatay, Turkey
}

\section{A R T I C L E I N F O}

\section{Keywords:}

Toxoplasma gondii

Diabetic patients

Seroprevalence

ELISA

\begin{abstract}
A B S T R A C T
Backgound: In some recent studies, it has been suggested that there may be a relationship between Toxoplasma gondii (T. gondii) and type 2 diabetes mellitus (T2DM). T. gondii is of greater significance in these patients. Objectives: In the present study, it was aimed to investigate the seroprevalence of $T$. gondii in T2DM patients. Methods: To define Toxoplasma IgG and IgM seropositivity and determine the seroprevalence of toxoplasmosis in patients presenting at the Internal Diseases outpatient clinic of the Healthcare Application and Research Hospital, where the ELISA method was used. 200 T2DM patients and 100 healthy individuals with no complaints took part in the study.

Results: Toxoplasma IgG positivity was determined in 53\% of the 200 T2DM patients and Toxoplasma IgM positivity in $13 \%$. While in the control group, Toxoplasma IgG positivity was determined in $27 \%$ and Toxoplasma IgM positivity in 1\%. The risk of toxoplasmosis infection in T2DM patients was two folds higher than healthy controls according to the IgG results. IgM results were further differentiated.

Conclusions: We believe that the seroprevalence of T. gondii is high in the T2DM patient group and that the causes should be investigated in more detail.
\end{abstract}

\section{Introduction}

Toxoplasma gondii (T. gondii) is an obligate intracellular parasite which creates infection in mammals and some bird species. T. gondii spreads to humans through the intake of food contaminated with oocysts found in cat feces or tissue cysts containing bradyzoites. ${ }^{1}$ It can also be spread by the consumption of infected raw or undercooked meat which can be spread by hand contact with infected meat. Mothers infected with $T$. gondii during pregnancy may pass the infection to the infant and the time of contracting the infection affects the degree of infection in the infant. ${ }^{2}$ The disease may be spread through various routes such as the placental route, blood transfusion or tissue transplantation. When the contagion pathways to humans are taken into consideration, the hands must be well washed with soap and water after contact with cats, gardening or any contact with soil bradyzoites. ${ }^{1}$

The rate of toxoplasmosis seropositivity in Turkey varies from region to region and according to research groups. ${ }^{3-5}$ In individuals with a healthy immune system, toxoplasmosis is generally seen to be asymptomatic. However, in patients with a suppressed immune system, a severe course is seen, and it may be fatal. By impairing both cellular and humoral immunity, malignant diseases, immunosuppressive treatment, corticosteroids, splenectomy, and radiotherapy may lead to reactivation of $T$. gondii in a latent state. ${ }^{6}$ Although there are a large number of studies on neurological disorders and cancer association with $T$. gondii, there is a minimal number of studies on the relationship with diabetes. ${ }^{7,8}$ Cellular immunity plays a role in the basis of the immune response of the host to T. gondii. T. gondii creates a dominant Thelper type 1 (Th1) cell-mediated inflammatory response. ${ }^{9}$ The ability of the host to control $T$. gondii depends on the subsequent production of interleukin (IL)-12 by macrophages and dendritic cells by Toll-like receptors. Also, IL-12 stimulates natural killer cells and CD4+ and $\mathrm{CD} 8+\mathrm{T}$ cells to release interferon gamma (IFN- $\gamma$ ). This situation provides the host resistance against $T$. gondii. IL-10, TGF- $\beta$, and IL-27 are vital down-regulators that prevent the overproduction of Th1-type cytokines, thereby regulating inflammation. ${ }^{9}$ Strong Th1 immune response leads to tachyzoites which turn into bradyzoites and leads to prolonged immunity. The infected host is asymptomatic at this time. ${ }^{9}$

Diabetes, which is currently widespread, is a chronic disease which develops with hyperglycemia and forms as a result of deficiencies in insulin hormone or an insufficient effect. There are two types of diabetes; insulin dependent (Type I) and non-insulin dependent (Type II). ${ }^{10}$ The main problem in Type I diabetes is the destruction of beta cells, Type II diabetes is associated with a family history and excessive body weight. Type II diabetes originates from the ineffective use of

\footnotetext{
* Corresponding author. Hatay Mustafa Kemal University, Faculty of Health Sciences, 31060, Hatay, Turkey.

E-mail addresses: semraozcelik@bezmialem.edu.tr (S. Ozcelik), mehtap.alim@outlook.com (M. Alim), necatiozpinar@gmail.com (N. Ozpinar).
} 
insulin in the body. Beta cell damage is a problem in both types of diabetes. ${ }^{10}$ Diabetes is among the diseases causing death in Turkey, following cardiovascular diseases and cancer. According to the results of the Turkish Diabetes Epidemiology II report (TURDEP), the rate of diabetic patients in Turkey is $13.7 \%$. The results of a study by the Turkish Ministry of Health stated that the prevalence of diabetes increased proportionally to age, and was seen at the rate of $30 \%$ in the 65-74 years age group. ${ }^{11}$ Proinflammatory cytokines have also been shown to be released in type 2 diabetes mellitus (T2DM). In T2DM patients, CD8 and CD16 values, which are markers for NK cells and suppressor T-cells in cellular immunity, in particular, are known to be lower than those of healthy individuals. ${ }^{9}$

In this study, the presence of $T$. gondii antibody was investigated in blood samples from 200 T2DM patients and 100 healthy control subjects in order to investigate the relationship between diabetes and $T$. gondii.

\section{Methods}

This cross-sectional study was performed on diabetic patients referred to Internal Diseases outpatient clinic of Healthcare Application and Research Hospital. All patients who were referred to the diabetes center and would like to contribute in our study were questioned about demographic characteristics, abortion, the habit of feeding cats and consumption of raw or undercooked meat. All patients and healthy individuals who gave written consent were recruited in this study using the convenience sampling method.

The study included the samples from 200 T2DM patients aged from 18 to 80 years old and samples from 100 healthy individuals as a control group. A blood sample of 2-3 ml was taken from patients aged. The blood sample was centrifuged at $1500 \mathrm{rpm}$ for $10 \mathrm{~min}$ for separation of the serum. The serum samples were stored at $-20{ }^{\circ} \mathrm{C}$ until assay. The Toxo-IgG and Toxo-IgM antibodies were investigated in the test serums with the ELISA method using Dia Pro (Italy) commercial kits. The ELISA was performed and evaluated according to the Dia Pro (Italy) kits procedure.

\subsection{Detection of Toxo-IgG}

The serums stored at $-20{ }^{\circ} \mathrm{C}$ and the kits stored at $2{ }^{\circ}-8{ }^{\circ} \mathrm{C}$ were taken to room temperature. The patient samples were diluted at the rate of 1:101 with $1000 \mu \mathrm{l}$ sample diluent $+10 \mu \mathrm{l}$ sample and $100 \mu \mathrm{l}$ was pipetted into wells from positive and negative controls and calibrators (1-6). The wells were marked and covered, then incubated at $37{ }^{\circ} \mathrm{C}$ for $60 \mathrm{~min}$. They were then washed 5 times in the washing device and $100 \mu \mathrm{l}$ enzyme conjugate was added to the wells and incubated again at $37^{\circ} \mathrm{C}$ for $60 \mathrm{~min}$. They were then washed 5 times in the washing device and $100 \mu \mathrm{l}$ chromogen substrate was added to the wells and incubated in the dark at room temperature $\left(18^{\circ}-24^{\circ} \mathrm{C}\right)$ for $20 \mathrm{~min}$. Stop solution of $100 \mu \mathrm{l}$ was added to all the wells and the samples were then examined with the ELISA reader (Labomed EMR-500, USA) at $450 \mathrm{~nm}$ wavelength.

\subsection{Detection of Toxo-IgM}

The serums stored at $-20{ }^{\circ} \mathrm{C}$ and the kits stored at $2^{\circ}-8{ }^{\circ} \mathrm{C}$ were taken to room temperature. The patient samples were diluted at the rate of 1:101 with $1000 \mu \mathrm{l}$ sample diluent $+10 \mu \mathrm{l}$ sample and $100 \mu \mathrm{l}$ was pipetted into wells from the controls and calibrators and $100 \mu \mathrm{l}$ was added from the diluent. The samples were kept at $37{ }^{\circ} \mathrm{C}$ for $60 \mathrm{~min}$ then washed 5 times with $60 \mathrm{ml}$ Washbuf $1200 \mathrm{ml}$ distilled water. Diluent of $1.9 \mu \mathrm{l}$ was added to Toxo IgM Ag and antigen antibody complex was formed by adding $100 \mu \mathrm{l}$ from the conjugate to each of the Toxo Ag. From the prepared antigen-antibody complexes, $100 \mu \mathrm{l}$ was added to each of the wells and they were kept at $37^{\circ} \mathrm{C}$ for $60 \mathrm{~min}$, then washed 5 times with $60 \mathrm{ml}$ Washbuf $1200 \mathrm{ml}$ distilled water. $100 \mu \mathrm{l}$ chromogen substrate was added to all the wells and incubated in the dark at room temperature for $20 \mathrm{~min}$. Absorbance plate wells were read at a wavelength of $450 \mathrm{~nm}$ with a plate reader (Labomed EMR-500, USA).

\subsection{Statistical analysis}

The row data was entered and analyzed by the SPSS v22.0 statistics program. In the evaluation of the data, as the parametric test assumptions were not met, the Kruskal Wallis test, the Mann Whitney $U$ test, and the Chi-Square test were used. A value of $p<0.05$ was accepted as statistically significant.

\section{Results}

Serum samples collected from 200 T2DM patients were examined for T. gondii antibodies with the ELISA method. The results were compared with those of serum samples collected from 100 healthy individuals.

Toxoplasma Ig antibodies were found to be positive with the ELISA method in $106(53.0 \%)$ of the 200 T2DM patients. This rate was determined as $27 \%$ in the control group. There was a significant difference between the groups $(\mathrm{p}<0.05)$. The distribution of Toxoplasma IgG results of diabetic and control groups according to gender is shown in Table 1.

Toxoplasma IgM antibody positivity was determined in 26 (13\%) patients of the patient group and only 1 of the control group. There was a significant difference between the groups $(\mathrm{p}<0.05)$. The distribution of Toxoplasma IgM results of diabetic and control groups is shown in Table 2. In 15 patients of the T2DM group, positivity was determined in both antibodies. Distribution of all results obtained with ELISA of the diabetic and control groups is shown in Table 3.

In the T2DM patient group, IgG positivity alone was determined in $81(40.5 \%)$ patients demonstrating the previous toxoplasmosis. It can be said that 15 patients were infected. The IgM positivity alone was determined in 11 patients which necessitated the evaluation of these results together with clinical signs. In this evaluation, it should not be forgotten that toxoplasmosis may be seen as asymptomatic.

\section{Discussion}

This study found out that, $53 \%$ of T2DM patients and $27 \%$ of nondiabetic controls were positive for the Toxoplasma IgG antibodies. Also, $13 \%$ of T2DM patients and $1.0 \%$ healthy controls were positive for the anti-IgM antibodies. According to the hypotheses put forward in this respect, either $T$. gondii is caused by diabetes, or $T$. gondii may be more easily found in patients with diabetes. This association is the ability of T. gondii to spread quickly to all nucleated cells and to replicate rapidly in the presence of glucose. There are very few epidemiological studies referring to this association. ${ }^{12-17}$ When these publications are evaluated, the following information was reached and summarized in Table 4.

Hokelek et al. ${ }^{13}$ a group of 56 T2DM patients, treated and followed

Table 1

Distribution of the anti-Toxo IgG results of the diabetic and control groups (N: Number).

\begin{tabular}{lllllll}
\hline Group & \multicolumn{2}{l}{ ELISA IgG } & \multicolumn{3}{l}{ Total } \\
\cline { 2 - 7 } & Pozitive & \multicolumn{3}{c}{ Negative } \\
\cline { 2 - 7 } & $\mathrm{N}$ & $\%$ & $\mathrm{~N}$ & $\%$ & $\mathrm{~N}$ & $\%$ \\
\hline $\begin{array}{llllll}\text { Diabetes } \\
\text { Control }\end{array}$ & $108^{*}$ & 54.0 & 92 & 46.0 & 200 & 100 \\
Total & $66^{*}$ & 66.0 & 34 & 34.0 & 100 & 100 \\
& 174 & & 126 & & 300 & 100 \\
\hline
\end{tabular}

$* ; \mathrm{p}<0.05$, Chi square test. 
Table 2

Distribution of the anti-Toxo IgM results of the diabetic and control groups.

\begin{tabular}{lllllll}
\hline \multirow{2}{*}{ Group } & \multicolumn{2}{l}{ ELISA IgG } & \multicolumn{3}{l}{ Total } \\
\cline { 2 - 7 } & Pozitive & \multicolumn{3}{l}{ Negative } \\
\cline { 2 - 7 } & $\mathrm{N}$ & $\%$ & $\mathrm{~N}$ & $\%$ & $\mathrm{~N}$ & $\%$ \\
\hline $\begin{array}{l}\text { Diabetes } \\
\text { Control }\end{array}$ & $26^{*}$ & 13.0 & 174 & 87.0 & 200 & 100 \\
\hline
\end{tabular}

$* ; p<0.05$, Fisher's exact test.

Table 3

Distribution of the results obtained with ELISA of the diabetic and control groups (N: Number).

\begin{tabular}{lllllllll}
\hline Group & IgG + IgM & IgG & & IgM & \multicolumn{3}{c}{$(-)$} & \\
\cline { 2 - 8 } & $\mathrm{N}$ & $\%$ & $\mathrm{~N}$ & $\%$ & $\mathrm{~N}$ & $\%$ & $\mathrm{~N}$ & $\%$ \\
\hline Diabetes & 15 & 7.5 & 81 & 40.5 & 11 & 5.5 & 83 & 41.5 \\
Control & 1 & 1.0 & 26 & 26.0 & 0 & 0.0 & 73 & 73.0 \\
\hline
\end{tabular}

up at the endocrinology outpatient clinic, and a control group of 46 healthy individuals was examined. The mean age was 59.1 years. IgG seropositivity was determined in $41(73.2 \%)$ of the 56 patients and IgM seropositivity in $1(1.8 \%$ ) while the rates in the control group were 1/46 $(2.2 \%)$ for IgG seropositivity and no IgM seropositivity was determined. The rate of IgG seropositivity determined in the T2DM patient group compared to the control group was evaluated as statistically different. Even though the possibility of $T$. gondii is increased at an older age, the IgG seropositivity was at a higher level compared to the control group. Gokce et al. ${ }^{12}$ aimed to determine the seroprevalence of Toxoplasma antibodies using the micro enzyme-linked immunosorbent assay and indirect fluorescent antibody technique in 85 T2DM patients and 85 healthy individuals. Toxoplasma IgG seropositivity was determined in $49(56.62 \%)$ of the T2DM patients and $18(21.2 \%)$ of the control group. This result was found to be highly statistically different. IgM was determined negative in both groups. It was stated that parasitology follow-up was necessary for the patient group. In another previous study in Iran of 184 serum samples from 91 diabetic patients and 93 control groups, were studied using the ELISA method. The risk of $T$. gondii infection in diabetic patients was reported to be 2 -fold higher than in the healthy control group. Toxoplasma IgG antibody prevalence was determined as $60.43 \%$ in the diabetic patient group and $38 \%$ in the control group. According to this result, patients with toxoplasmosis were reported to be more sensitive than those without diabetes. It was reported that diabetes which could occur through $T$. gondii caused damage to the nerve cells and directly to the pancreas cells in the presence of $T$. gondii and with the elimination of beta cells, insulin expression was more affected. ${ }^{16}$ In another study in Iran, the presence of Toxoplasma antibodies was examined in 205 blood samples taken from diabetic patients, comprising 42 males and 163 females, aged 13-60 years. Of these cases, 60 (29.3\%) were reported seronegative, and 145 $(70.7 \%)$ were seropositive. In $36.6 \%$ of patients IgG + IgM positivity (acute phase) was determined, in 49.6\%, IgG (+) but IgM (-) (chronic phase) and in $13.8 \%$, false positivity. The relationship between toxoplasmosis and diabetes was evaluated using the Chi-square test $(\mathrm{p}<0.05)$. A statistical difference was determined in respect of age, gender, meat consumption, fasting blood glucose and the presence of Toxoplasma antibodies ( $\mathrm{p}<0.05$ ). The seroprevalence of Toxoplasma IgM and IgG antibodies was observed to be high in females. It was reported that toxoplasmosis could not be fully controlled in diabetic patients and therefore, it was necessary to periodically monitor the antibody level against $T$. gondii in the patient group. ${ }^{14}$

In the current study of $200 \mathrm{~T} 2 \mathrm{DM}$ patients, Toxoplasma IgG positivity was determined in $106(53.0 \%)$ patients and the control group, positivity was determined in $27(27.0 \%)$. There was a significant difference between the two groups was found to be statistically.

Toxoplasma IgM seropositivity was determined at the rate of $13 \%$ in the patient group and $1.0 \%$ in the control group. This result was statistically different. From the result that IgG positivity alone was determined in 81 (40.5\%), it was understood that these individuals had previously experienced toxoplasmosis. It was concluded that in 26 cases, the infection was at the initial stage and 15 cases were infected. Evaluation of these results together with clinical signs is required. The risk of toxoplasmosis was seen to be two-fold higher in diabetic patients than in the control group. The results were seen to be consistent with the findings of previous studies. This study is important because it shows the relationship between Toxoplasmosis and T2DM. Also, the relationship between Toxoplasmosis and T2DM can be confirmed by a larger sample group and high-precision analyzes like PCR.

\section{Conclusion}

Opportunistic infections such as toxoplasmosis are more often encountered in diabetic patients than in healthy individuals. These individuals are more prone to infections. It would, therefore, be appropriate to evaluate these patients periodically in respect of toxoplasmosis. Routine screening for T. gondii infection in T2DM patients would add to the risk prediction.

\section{Ethics approval}

The present study was conducted according to the principles of the Declaration of Helsinki. Approval for this study was granted by the Clinical Research Ethics Committee of Cumhuriyet University with decision no. 2015-03/01, dated 10.03.2015.

\section{Funding}

This study was funded by the Cumhuriyet University Scientific Research Projects Unit (T-635).

\section{Financial interest}

The authors listed above have no financial interest with any company or organization in the subject matter or materials discussed in this

Table 4

Studies on serprevalence of T.gondii in T2DM patients.

\begin{tabular}{|c|c|c|c|c|c|c|c|}
\hline Reference & $\mathrm{N}$ & Age & Diagnostic method & Control T.gondii IgG + & $\begin{array}{l}\text { Control T.gondii } \\
\operatorname{IgM}+\end{array}$ & $\begin{array}{l}\text { T2DM and T.gondii } \\
\text { IgG }+\end{array}$ & T2DM and T.gondii IgM + \\
\hline Hokelek et al., $2000^{13}$ & $56+46$ & Adults & ELISA & $1 / 46(2.2 \%)$ & no & $41 / 56(73.3 \%)$ & $1 / 56(1.8 \%)$ \\
\hline Gokce et al., $2008^{12}$ & $85+85$ & Adults & ELISA and IFAT & $18 / 85(21.2 \%)$ & no & $49 / 85(56.6 \%)$ & no \\
\hline Shirbazou et al., $2013^{16}$ & $91+93$ & Adults & ELISA IgG & $36 / 93(38.0 \%)$ & Not studied & $55 / 9160.43 \%$ & Not studied \\
\hline Siyadatpanah et al., $2013^{17}$ & $150+150$ & Adults & ELISA & $79 / 150(52.6 \%)$ & - & $76 / 150(50.6 \%)$ & - \\
\hline Modrek et al., $2015^{14}$ & $205+0$ & $13-60$ & ELISA & - & - & $125 / 205(70.7 \%)$ & $73 / 205(35.6 \%)$ \\
\hline Saki et al., $2016^{15}$ & $110+110$ & Adults & ELISA & $47 / 110(42.7 \%)$ & - & $24 / 110(21.8 \%)$ & - \\
\hline Present study & $200+100$ & Adults & ELISA & $27 / 100(27 \%)$ & $1 / 100(1 \%)$ & $106 / 200(53 \%)$ & $26 / 200(13 \%)$ \\
\hline
\end{tabular}


manuscript.

\section{Declaration of competing interest}

The authors declare no conflict of interest.

\section{References}

1. Robert-Gangneux F, Darde ML. Epidemiology of and diagnostic strategies for toxoplasmosis. Clin Microbiol Rev. 2012;25(2):264-296. https://doi.org/10.1128/CMR. 05013-11.

2. Many A, Koren G. Toxoplasmosis during pregnancy. Can Fam Physician. 2006;52(1):29-30http://www.cfp.ca/content/52/1/29.short.

3. Alver O, Goral G, Ercan I. Investigation of serological results of patients with suspected toxoplasmosis admitted to the ELISA laboratory of Uludag University Hospital between 2002-2008. Turk J Parasitol. 2014;38(3):141https://pdfs.semanticscholar. org/43ac/9fa84f9ac688db9e184d818c2306c7b77dde.pdf.

4. Dogan K, Guraslan H, Ozel G, Aydan Z, Yasar L. Seroprevalence rates of Toxoplasma gondii, rubella, cytomegalovirus, syphilis, and hepatitis $\mathrm{B}$, seroprevalences rate in the pregnant population in Istanbul. Turk $J$ Parasitol. 2014;38(4):228http://www. turkiyeparazitolderg.org/sayilar/56/buyuk/228-233.pdf.

5. Yildirim D, Buyukboyaci NH, Bolukbasi S, et al. Investigation of Toxoplasma gondii seropositivity in toxoplasmosis suspected patients by chemiluminescent microparticle immunological test (CMIA). Cumhuriyet Med J. 2013;35(4):468-474. https:// doi.org/10.7197/1305-0028.2260.

6. Filisetti D, Candolfi E. Immune response to Toxoplasma gondii. Ann Ist Super Sanita. 2004;40(1):71-80http://old.iss.it/binary/publ/publi/40171.1107854946.pdf.

7. Cevizci S, Tunga Babaoglu U, Gulec Oyekcin D. Toxoplasma gondii, mental health and schizophrenia. TAF Prev Med Bull. 2013;12(2):199-208. https://doi.org/10.5455/ pmb1-1337514352.

8. Alim M, Ozcelik S, Ozpinar N. Seroprevalence of Toxoplasma gondii in patients receiving cancer treatment. Cumhuriyet Med J. 2018;40(1):731-736. https://doi.org/ 10.7197/223.vi.387046.

9. Nosaka K, Hunter M, Wang W. The role of Toxoplasma gondii as a possible inflammatory agent in the pathogenesis of type 2 diabetes mellitus in humans. Fam Med Commun Health. 2016;4(4):44-62. https://doi.org/10.15212/FMCH.2016.0128.

10. Pickup JC. Inflammation and activated innate immunity in the pathogenesis of type 2 diabetes. Diabetes Care. 2004;27(3):813-823. https://doi.org/10.2337/diacare.27.3. 813.

11. Satman I, Omer B, Tutuncu Y, et al. Twelve-year trends in the prevalence and risk factors of diabetes and prediabetes in Turkish adults. Eur $J$ Epidemiol. 2013;28(2):169-180. https://doi.org/10.1007/s10654-013-9771-5.

12. Gokce C, Yazar S, Bayram F, Gundigan K. Toxoplasma gondii antibodies in type 1 diabetes mellitus. Turkiye Klinikleri J Med Sci. 2008;28(5):619-622https://www.ncbi. nlm.nih.gov/pubmed/18472707.

13. Hokelek M, Kahraman H, Uyar Y, Gudul Havuz S. Seroprevalence of Toxoplasma antibodies in patients with type II diabetes mellitus. Clin Sci Dr. 2000;6(3):302-304http://www.turkmedline.net/detay.html?id $=3260934752429 \mathrm{ce}$ \&language $=$ tr\&mysearchvalue $=128 \% 202000 \% 206 \% 203$.

14. Modrek MJ, Saravani R, Mousavi M, Khorashad AS, Piri M. Investigation of IgG and IgM antibodies against Toxoplasma gondii among diabetic patients. Int J Infect 2015;2(3):1-5. https://doi.org/10.17795/iji27595.

15. Saki J, Shafieenia S, Foroutan-Rad M. Seroprevalence of toxoplasmosis in diabetic pregnant women in southwestern of Iran. J Parasit Dis. 2016;40(4):1586-1589https://link.springer.com/article/10.1007/s12639-0150735-4.

16. Shirbazou S, Delpisheh A, Mokhetari R, Tavakoli G. Serologic detection of antiToxoplasma gondii infection in diabetic patients. Iran Red Crescent Med J. 2013;15(8):701https://www.ncbi.nlm.nih.gov/pmc/articles/PMC3918195.

17. Siyadatpanah A, Tabatabaie F, Oormazdi H, Reza A, Meamar E, Hadighi R Comparison of anti-toxoplasma IgG and IgM antibodies determined by ELISA method in diabetic and non-diabetic individuals in west Mazandaran province, Iran, 20112012. Ann Biol Res. 2013;4(6):281-285. 